\title{
Pulmonary Thromboembolism and Intracardiac Thrombus as a Presentation of Behcet's Disease
}

\section{Joana Neves ${ }^{1 *}$, Lília Andrade ${ }^{2}$ and Alcina Saraiva ${ }^{3}$}

${ }^{1}$ Interna de Formação Específica de Medicina Interna, Serviço Medicina II, Centro Hospitalar Baixo Vouga - Aveiro, Portugal

${ }^{2}$ Assistente Hospitalar de Pneumologia, Serviço Pneumologia, Centro Hospitalar Baixo Vouga - Aveiro, Portugal

${ }^{3}$ Assistente Hospitalar Graduada de Pneumologia, Serviço Pneumologia, Centro Hospitalar Baixo Vouga - Aveiro, Portugal

\begin{abstract}
Behçet's disease is a multi systemic vasculitis whose presentation does not always meet the typical triad of orogenital ulceration, skin and ocular lesions. Right ventricular thrombus, thromboembolism and pulmonary artery aneurysms are rare manifestations and associated with poor prognosis. The authors describe the clinical case of a 38 year old man with multiple admissions for respiratory infection and erythema nodosum. A chest angiotomography revealed pulmonary thromboembolism and right ventricular thrombus, without other changes in laboratory tests. The patient did not take the prescribed oral anticoagulation and abandoned follow up, was admitted two years later with a similar clinic and recurrent oral ulceration. New thromboembolic and angiography showed aneurysmal dilatation of the pulmonary arteries. Behcet's disease was diagnosed. Corticosteroid therapy was started with a good response after one month.
\end{abstract}

Keywords: Behçet; Pulmonary thromboembolism; Intracardiac thrombus; Pulmonary artery aneurysms

\section{Introduction}

Behçet's disease (BD) is a chronic, multi systemic vasculitis of unknown etiology that primarily affects men, in the third and fourth decades of life. It is more prevalent in the middle and far east and the Mediterranean bay, where a high prevalence of $80-370$ cases per 100,000 habitants has been described [1]. It characteristically presents with recurrent orogenital ulceration, skin and ocular lesions, but may also be associated with neurological, gastrointestinal, joint and cardiovascular involvement. The vascular involvement is common (5-30\%), particularly venous involvement [2-4]. Aneurysmal formations are more frequent than arterial occlusion, and are one of the most serious complications, due to the risk of rupture. The abdominal aorta isthe most common site of aneurysms ( $60 \%$ of cases), followed by the pulmonary artery $[2,3]$. Pulmonary involvement is rare, occurring in 1 to $7.7 \%$ of cases, and includes, among others, pulmonary artery aneurysms, arterial and venous thrombosis, pulmonary infarction and recurrent pneumonia $[1,3,5]$. Pulmonary artery aneurysms are the most common pulmonary manifestations, and Behçet's disease is the most common cause of those [3,6-8]. Pulmonary arterial thromboembolism is a very rare manifestation, almost always associated with vasculitic phenomena in pulmonary artery and with right intra cavitary thrombus, and with no relation to venous thrombosis, despite its high prevalence [4]. Cardiac manifestations are alsorare, about $1-5 \%$,and are associated with poor prognosis $[3,4]$. Intra cavitary thrombus is read in the literature only 50 cases $[3,4,9]$.

\section{Clinical Case}

We present the case of a 38 year old Caucasian male who was a smoker but otherwise previously healthy. In 2008 he had three hospital admissions for lower respiratory tract infections with chestpain, dyspnoea, fever, cough with occasional haemoptysis and erythemanodosum. At the last admission, chest radiograph showed peripheralhy po transparent lesions, with triangular shape, which raised the suspicion of pulmonary embolism, confirmed by chest CT angiography. This exam also detected a mass with $30 \times 22 \mathrm{~mm}$, adherent to the free wall oftherightventricle, compatible with intracavitary thrombus, later confirmed by cardiac magnetic resonance imaging (Figure 1). The doppler ultrasound of the lower limbs showed no changes and serological screening for autoimmune diseases or thrombophilic changes was negative. Oral anticoagulation was prescribed, but the patient failed to attend follow-up appointments.

In 2010 he was admitted at the emergency department, with complaints suggestive of respiratory infection, erythemanodosum and exuberantand recurrent oral ulceration, duringthelast year. He was not taking any therapy. He was admitted as an inpatient at the for furthe revaluation. Diagnostic investigations revealed: sedimentation rate of $93 \mathrm{~mm}$ at the $1^{\text {st }}$ hour; proteinuria $(<1 \mathrm{~g} / 24 \mathrm{~h})$ without changes in

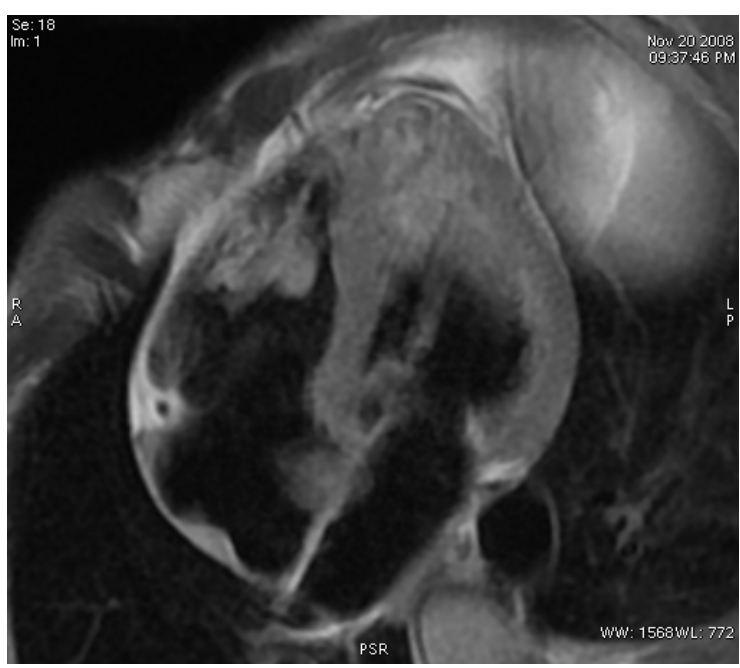

Figure 1: Intracavitary thrombus in cardiac magnetic resonance.

*Corresponding author: Joana Neves, Interna de Formação Específica de Medicina Interna, Serviço Medicina II, Centro Hospitalar Baixo Vouga - Aveiro, Portugal, Tel: +49 622156 4582; E-mail: joana.brrneves@gmail.com

Received November 05, 2013; Accepted December 09, 2013; Published December 11, 2013

Citation: Neves J, Andrade L, Saraiva A (2013) Pulmonary Thromboembolism and Intracardiac Thrombus as a Presentation of Behçet's Disease. J Pulm Respir Med 3: 162. doi:10.4172/2161-105X.1000162

Copyright: $\odot 2013$ Neves J, et al. This is an open-access article distributed under the terms of the Creative Commons Attribution License, which permits unrestricted use, distribution, and reproduction in any medium, provided the original author and source are credited. 


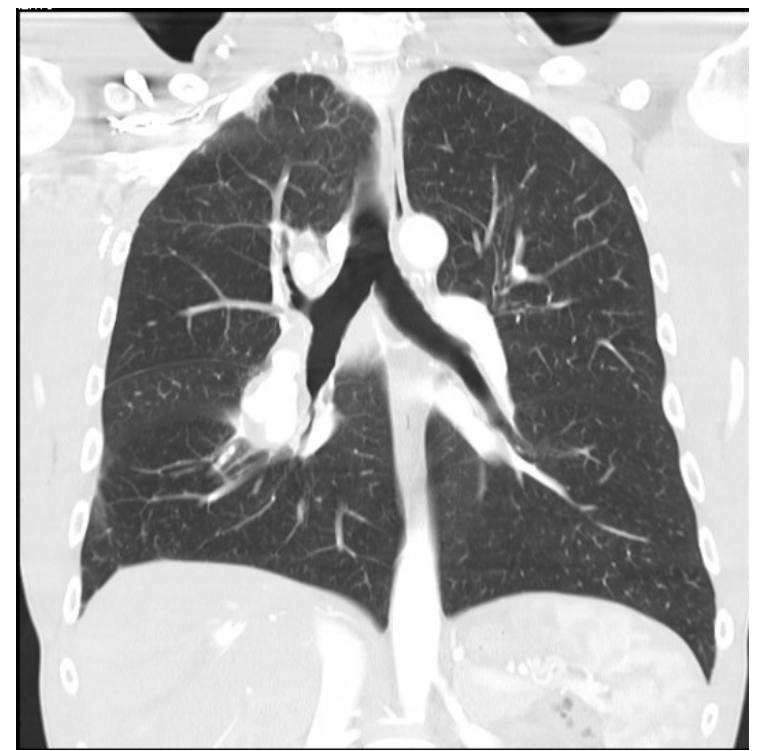

Figure 2: Aneurysmatic dilatations of pulmonary artery in a thorax computed tomography.

renal function; antiphospholipid antibodies, antinuclear antibodies and Anti-neutrophil cytoplasmic antibodies were negative; thrombophilia investigation was negative; hyper homocysteinemia of $18 \mathrm{mmol} / \mathrm{l}$ (for a normal 5-15 mmol/l); presence of the HLA - B51 allele was identified. Echocardiography revealed a decrease of thrombus dimension $(22 \times 10$ $\mathrm{mm}$ ) and chest computed tomography demonstrated thromboembolic pulmonary arteries with dilatations in the apical segment of the right lower lobe. Doppler (Figure 2) ultrasound of the lower limbs showed recanalization phenomena of previous thrombosis. The pathergy test was positive and there were superficial phlebitis of the upper arm secondary to vene puncture. There were thus obtained the diagnostic criteria according to the $\mathrm{BD}$ "International Criteria for Behcet 's Disease “ (ICBD) $[10,11]$

The patient started corticosteroid therapy with prednisolone at a dose of $1 \mathrm{mg} / \mathrm{kg}$ body weight, with significant clinical improvement after one month of treatment, but was again lost to follow-up due to socio-economic reasons.

\section{Discussion}

Although venous thrombosisis a frequent manifestation of $\mathrm{BD}$ (10-30\%), pulmonary thromboembolismis a rare feature [2]. The low incidence of pulmonary thromboembolism in this pathology, despite the prothrombotic state associated with it, is due to the fact that the thrombusis ordinarily adherent to the sides of the vasculature [4]. In this case, the presence of thrombusand the intracavitary pulmonary thrombosis in situ, associated with pulmonary artery aneurysms are possible sources of thromboembolism [2,3]. Apost-mortemstudyof 23,796 patients concluded that of the 354 patients who had pulmonary embolism and right intracardiac thrombus, the thrombus was the only source of embolization in 62.1\% [12]. In 2000, Mogulkoç et al. published a review of 25 patients with $\mathrm{BD}$ with intracardiac thrombus. Among these, pulmonary thromboembolism was observed in 13 patients (52\%) [9]. The exact pathophysiological mechanism of the prothrombotic tendency of BD remains unknown, but it is assumed that some thrombophilic factors may contribute, such as hyperhomocysteinemia, present in this patient (homocysteine $18 \mathrm{mmol} / \mathrm{L}$ ). In a study in patients with $\mathrm{BD}$ higher values of homocysteine were observed in the group with thrombotic events, suggesting that hyperhomocysteinemia may be an independent risk factor for thrombosis $[13,14]$.

Intracardiac thrombosis is an extremely rare event and may precede in years other disease manifestations, including oral ulcers, and should therefore always raise the suspicion of $\mathrm{BD}$ in the absence of other characteristics $[2,9,15]$. The mechanism of formation is still not well understood and may be due to a in situ process, secondary to venous thrombosis, to which it is often associated, or even to endomiocardic fibrosis [2]. It is more common in males and the right ventricle is the most common location ( $78 \%$ of cases) $[3,15]$. The thrombus is usually adherent to the myocardium and its presence is strongly associated with pulmonary artery aneurysms. Several cases in the literature describe the existenc eof intracardiac thrombosis and pulmonary artery aneurysms in $\mathrm{BD}$, or not associated with pulmonary thromboembolism [15-20]. In $33 \%$ ofpatients, pulmonary artery aneurysms are associated with a right ventricular thrombus [8]. Pulmonary artery aneurysms are typically located in the right lower lobeartery, with arterial thrombosis and associated to inflammatory phenomena [6-8]. Hemoptysis is the most common manifestation, present in $79 \%$ of cases. Cough, fever, dyspnea, pleuritic chest pain are also common features and can be interpreted as an infeccion [8]. In this case, is questionable if the symptoms are due to thromboembolic phenomena or to an early manifestation of the existence of pulmonary artery aneurysms, not observed in the first angiography. Fever (52\%), hemoptysis (48\%), dyspnea (44\%) and cough $(20 \%)$ can also be the symptoms of intracardiac thrombus [9]. Recommended treatment in severe forms of vasculitis, as presented, is the combination of corticosteroids and immunosuppressive drugs, being cyclophosphamide the first-line therapy for patients with $\mathrm{BD}$ and vascular involvement $[1,2,9]$. The presence of thromboembolic and cardiacthrombus initially imposed hypocoagulation; however, in face of the subsequent diagnosis of aneurysms of the pulmonary artery (which confers a great morbidity and mortality due to the risk of rupture and fistulization when associated with an increased of pulmonary artery pressure), anticoagulants were not restarted because of the increased bleeding risk [8].

We emphasizes a case of $\mathrm{BD}$ with a rare form of presentation, within frequent but potentially serious cardiopulmonary manifestations, with an a typical progression of symptoms.

\section{References}

1. Erkan F, Gül A, Tasali E (2001) Pulmonary manifestations of Behçet's disease. Thorax 56: 572-578

2. Owlia MB, Mehrpoor G (2012) Behcet's Disease: New Concepts in Cardiovascular Involvements and Future Direction for Treatment. ISRN Pharmacol 2012: 760484.

3. Chae EJ, Do KH, Seo JB, Park SH, Kang JW, et al. (2008) Radiologic and clinical findings of Behçet disease: comprehensive review of multisystemic involvement. Radiographics 28: e31.

4. Seyahi E, Yurdakul S (2011) Behçet's Syndrome and Thrombosis. Mediterr J Hematol Infect Dis 3: e2011026.

5. Așker S, Așker M, Gürsu O, Mercan R, Timuçin OB (2013) A Behcet's Disease Patient with Right Ventricular Thrombus, Pulmonary Artery Aneurysms, and Deep Vein Thrombosis Complicating Recurrent Pulmonary Thromboembolism. Case Rep Pulmonol 2013: 492321.

6. Uzun O, Akpolat T, Erkan L (2005) Pulmonary vasculitis in behcet disease: a cumulative analysis. Chest 127: 2243-2253.

7. Nguyen ET, Silva Cl, Seely JM, Chong S, Lee KS, et al. (2007) Pulmonary artery aneurysms and pseudoaneurysms in adults: findings at CT and radiography. AJR Am J Roentgenol 188: W126-134.

8. Seyahi E, Melikoglu M, Akman C, Hamuryudan V, Ozer H, et al. (2012) Pulmonary artery involvement and associated lung disease in Behçet disease: a series of 47 patients. Medicine (Baltimore) 91: 35-48. 
Citation: Neves J, Andrade L, Saraiva A (2013) Pulmonary Thromboembolism and Intracardiac Thrombus as a Presentation of Behçet's Disease. J Pulm Respir Med 3: 162. doi:10.4172/2161-105X.1000162

9. Mogulkoc N, Burgess MI, Bishop PW (2000) Intracardiac thrombus in Behçet's disease: a systematic review. Chest 118: 479-487.

10. [No authors listed] (1990) Criteria for diagnosis of Behçet's disease. International Study Group for Behçet's Disease. Lancet 335: 1078-1080.

11. Davatchi F (2012) Diagnosis/Classification Criteria for Behcet's Disease. Patholog Res Int 2012: 607921

12. Ogren M, Bergqvist D, Eriksson H, Lindblad B, Sternby NH (2005) Prevalence and risk of pulmonary embolism in patients with intracardiac thrombosis: a population-based study of 23796 consecutive autopsies. Eur Heart J 26: 11081114.

13. Hammami S, Addad F, Kaoubaa N, Golli M, Chebbi W, et al. (2006) [Pulmonary embolism and Behçet's disease]. Arch Mal Coeur Vaiss 99: 786-790.

14. Shahram F, Faridar A, Hamedani MG, Nadji A, Naderi N, et al. (2010) Plasma homocysteine level in patients with Behcet's disease with or without thrombosis. Arch Iran Med 13: 476-481.

15. Hammami R, Abid L, Frikha F, Marzouk S, Tounsi A, et al. (2012) Intracardiac thrombus in a young man: don't forget Behçet's disease! Intern Med 51: 18651867.

16. Zaghba N, Ech-cherrate A, Benjelloun H, Yassine N, Bakhatar A, et al. (2012 [Cardiac thrombosis, pulmonary artery aneurism and pulmonary embolism revealed Behçet's disease]. Rev Pneumol Clin 68: 307-310.

17. Chang JE, Lee YH, Lee J (2008) Multiple cardiovascular complications in a patient with Behcet's disease. Korean J Intern Med 23: 100-102.

18. Marc K, Iraqui G, Jniene A, Benamor J, Bourkadi JE (2008) [Intracardiac thrombus and pulmonary artery aneurysm in Behcet's disease]. Rev Mal Respir 25: 69-72.

19. Chiari E, Fracassi F, D'Aloia A, Vizzardi E, Zanini G et al. (2008) Right ventricular thrombus and pulmonary thromboembolism/thrombosis in Behçet's disease: a case report. J Am Soc Echocardiogr 21: 1079.

20. Ernam D, Atalay F, Alp A, HasanoÄŸlu HC (2006) A Behçet's disease patient with intracardiac thrombus, pulmonary artery aneurysms complicating recurrent pulmonary thromboembolism. Tuberk Toraks 54: 168-171. 